\title{
El cirujano antifrágil
}

\section{The antifragile surgeon}

Alberto Campos*
* Correspondencia: Dr. Alberto Campos E-mail: alberto campos@hotmail.com https://orcid.org/0000-0001-5811-1908

\section{Palabras clave: COVID-19, cirugía, antifrágil, resiliencia, robustez. \\ Keywords: COVID-19, surgery, antifragile, resilience,} robustness.

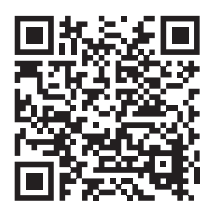

\section{RESUMEN}

En este artículo discuto cómo, en la incertidumbre, nuestras inferencias pueden ser optimistas sin una base firme y cómo la inducción crea una falsa confianza que impide la anticipación de eventos catastróficos. Explica las cualidades 'fragilidad', 'robustez' y 'antifragilidad' en sistemas biológicos y humanos. Finalmente, discuto las estrategias de antifragilidad profesional del cirujano para minimizar el daño y continuar con su trabajo.

\section{ABSTRACT}

In this article I discuss how, in uncertainty, our inferences can be optimistic without a firm foundation and how induction creates a false confidence that prevents the anticipation of catastrophic events. It explains the qualities 'fragility,' 'robustness,' and 'anti-fragility' in biological and human systems. Finally, I discuss the surgeon's professional anti-fragility strategies to minimize damage and continue her work.
El viento apaga una vela y energiza el fuego. Lo mismo con el azar, la incertidumbre, el caos: deberías usarlos, no esconderte de ellos. Deberías ser el fuego y desear el viento. Nassim Taleb

\section{INDUCCIÓN: DERIVAR TEORÍAS A PARTIR DE OBSERVACIONES}

$\mathrm{T}$ enemos la idea de que el conocimiento científico deriva de observaciones o de experimentos. Sin embargo no es tan fácil, como se supondría, establecer un hecho científico. Antes es preciso determinar si un conjunto de observaciones es sólido, si los estándares de prueba son suficientes y si son aceptados por la comunidad científica.

Ante la incertidumbre, nos encontramos en la situación de la gallina o el huevo, cuáles observaciones conformarán una teoría predictiva o si una teoría —en tanto conjunto de hipótesis- puede derivarse de observaciones que luego puedan generalizarse. Por momentos, el investigador y el médico se encuentran en esa situación incómoda.

¿Qué tipo de argumentos ordenados nos permiten ir de las observaciones a hechos que esperamos deducir lógicamente de ellas? Algunos argumentos, tomados como premisas, son sencillos. Por ejemplo el silogismo (1) Todos los hombres son mortales, (2) Sócrates es hombre, por lo tanto (3) Sócrates es mortal. Las premisas (1) y (2) son verdaderas, y (3) la conclusión también lo es.

Pero la vida real no tiene la lógica de un silogismo. Consideremos (1) Algunos libros de poesía son aburridos, (2) este es un libro de poesía, por lo tanto (3) este libro es aburrido. La conclusión (3) no necesariamente se sigue de (1) y (2), aunque sean verdaderas.

El problema surge cuando el cuantificador 'algunos' se interpreta como 'todos'. A la pregunta por qué creemos que el Sol saldrá mañana podemos responder «porque sale todos los días». Incluso podríamos agregar «siempre». Tenemos esa firme creencia porque el Sol siempre ha salido en el pasado, e inducimos que así será porque hemos observado la regularidad de ese fenómeno. No dudamos de que las leyes newtonianas del movimiento también sean operantes mañana, y no lo dudamos porque hasta ahora han funcionado.

'Todos' y 'siempre' son cuantificadores universales que aplicamos intuitivamente a

Citar como: Campos A. El cirujano antifrágil. Cir Gen. 2021; 43 (1): 60-66. https://dx.doi.org/10.35366/103917 
casos particulares, sin considerar que puede haber casos excepcionales. Por ejemplo, que un asteroide de unos 10 kilómetros de diámetro impacte la Tierra a más de 90,000 kilómetros por hora, arroje millones de toneladas de cenizas a la atmósfera, que regresen como lluvia incandescente y después la oscurezcan hasta impedir que la luz del Sol alcance la superficie, creando así una noche que extinga la mayor parte de la vida. La catástrofe sucedió hace 65 millones de años en Yucatán. Improbable e imposible no son sinónimos.

La experiencia parece mostrar que la repetición de una sucesión regular de eventos fuese la causa de tales eventos, cuando en realidad esa repetición sólo causa nuestra expectativa de que sucedan una o muchas veces más. Esta asociación de ideas produce en nosotros un hábito, el de crear leyes generales conocidas como «inferencias inductivas»; es decir, mediante un mecanismo de inducción formamos — con base en experiencias pasadas- conclusiones para el futuro.

La primera referencia conocida como «el problema de la inducción» remite a David Hume en su Tratado sobre la naturaleza humana (1739) y luego en la Investigación sobre el entendimiento humano (1748). La inducción crea un efecto de confianza que nos hace ignorar la posibilidad de eventos extraordinarios, sobre todo cuando las observaciones alentadoras son numerosas.

Pero con observaciones que se basan en nuestra percepción sensorial sólo podemos hacer predicciones limitadas. Cuando se trata de fenómenos biológicos, como esta pandemia, las relaciones causa-efecto no tienen la inmediatez de los fenómenos físicos. Además, la idea de pandemia y sus consecuencias es - por decir lo menos- muy desagradable. Por eso alguien lego en ciencia puede todavía negarse a creer que exista.

Es el caso que llamaré El Pavo Inductivista. En el ejemplo original, de Bertrand Russell ${ }^{2}$ es un pollo el que comete el error, pero el pavo de Taleb es más divertido. El Pavo sabe que todos los días el hombre lo alimenta, por lo que infiere dos conclusiones que adquieren estatuto de creencias; (1) con base en evidencia (isuena familiar?), que el hombre lo alimentará siempre; (2) con base en su pensamiento inductivo, que el hombre lo ama.
La inducción parece ser correcta hasta el día en que, en el pico de su confianza, su predicción falla. En la víspera de Navidad corregirá in extremis su creencia, justo antes de que el hombre le tuerza el cuello.

El Pavo pasó de un gran número de observaciones verdaderas a una conclusión (inducción) falsa. La experiencia nos hace creer que el Sol saldrá mañana, pero no estamos en una posición de certeza mejor que la de El Pavo (o el pollo).

Así, nuestras expectativas persisten a pesar de ser engañosas. Nuestras creencias en el futuro se sostienen en casos pasados cuya validez no hemos examinado detenidamente. Tendremos entonces que refinar nuestras expectativas futuras a partir de regularidades pasadas, preguntándonos si hay una base razonable para darles peso así como así, o cuestionar su validez. Como la gran cantidad de artículos publicados ante la urgencia sin una debida revisión por pares.

El error es cotidiano. Confundimos, como El Pavo, ausencia de evidencia (no hay nada agresivo en la conducta del granjero, siempre sonriente) con evidencia de ausencia (de la intención de engordarlo para Navidad). Esa intención bien pudo ser la causa de la sonrisa del granjero, malinterpretada por El Pavo. El pensamiento inductivo no puede ser ni probado ni invalidado por nuestras experiencias previas. Tampoco tenemos razón alguna para creer en la llamada «regularidad de la naturaleza». Con alguna frecuencia tenemos datos incompletos, sin evidencia de su verdad presente ni de su validez futura.

\section{FRAGILIDAD, ROBUSTEZ Y ANTIFRAGILIDAD}

Quien ha visto multitud de cisnes blancos podría argumentar que de acuerdo con sus datos es probable que todos los cisnes sean blancos. Si apareciera un cisne negro habría comprobado que puede suceder, a pesar de ser improbable que existan los cisnes negros. Pero improbable e imposible no son sinónimos. El evento de la torsión del cuello fue para el granjero un Cisne Blanco, otra Navidad con Pavo relleno al horno, pero fue un Cisne $\mathrm{Ne}-$ gro para El Pavo, quien confundió improbable 
con imposible. Por cierto, no todos los pavos son negros.

Los Cisnes Negros son acontecimientos a gran escala, de consecuencias masivas no previstas. Son eventos improbables y de impacto extremo, predecibles sólo en retrospectiva, cuando las piezas de la catástrofe encajan a posteriori.

Los procesos complejos económicos y sociales — como las devaluaciones, las protestas callejeras y las declaraciones de los políticostienen la volatilidad de lo aleatorio. ${ }^{3}$ Las zoonosis también tienen la volatilidad de lo aleatorio. Estos procesos pueden parecer estables durante mucho tiempo, sin variaciones extremas, como las cotizaciones de las monedas y las declaraciones de los políticos. Pero al someterse a grandes variaciones pueden tornarse caóticos, como las caídas de las bolsas de valores, las epidemias, o más todavía, esta pandemia.

Esta pandemia es un Cisne Negro. Durante años el sistema de salud resistió con una estabilidad precaria a pesar, entre otras cosas, de los recortes presupuestales, la carencia de insumos, la escasez de médicos y el aumento de la demanda de enfermos que por motivos económicos recurrían cada vez más a los servicios públicos de salud, a la par de las condiciones cada vez más difíciles impuestas por las aseguradoras y los altos costos de los servicios privados.

Antes del Cisne-Negro-CoV-2 la robustez del sistema de salud de México estaba sobrevaluada. Eso me hace recordar la canción del elefante (blanco) que se columpiaba sobre la tela de una araña. Como veía que resistía fue a llamar a otro elefante...... Y como resistía, a lo largo de diferentes administraciones se dejó a su resiliencia, la capacidad de soportar tensiones y volver al estado previo. Indefinidamente.

Como resistía, no se pensó que la erosión terminara por colapsarlo ante un evento catastrófico. La posibilidad de tal evento fue desestimada. Sus consecuencias complejas son, entre otras, el repunte de contagios, el aumento de la mortalidad, la pérdida de empleos, el aumento de la pobreza extrema y la presión sobre sistemas sociales interdependientes.

Pero también es ilusorio pensar que la sola planeación y los presupuestos resuelven los problemas emergentes. No es así. La incidencia de eventos futuros no puede medirse, no han sucedido. El riesgo tampoco puede medirse, sólo puede estimarse.

Sí pudo haberse medido la fragilidad del sistema, comparando el aumento paulatino en la demanda de servicios contra la disponibilidad y capacidad de los centros de atención. Habrían podido remediarse las carencias.

Con todo, un sistema de salud robusto tampoco habría sido suficiente para evitar el punto de inflexión de un evento aleatorio de gran magnitud y contener sus efectos. Los hospitales resilientes están teniendo de nuevo problemas por carencia, no sólo de ventiladores y personal capacitado sino de medicamentos para tratar a los enfermos. ${ }^{4,5}$ Ante un evento aleatorio extremo robusto y resiliente no bastan.

\section{ANTIFRAGILIDAD BIOLÓGICA}

Como no es posible una robustez a prueba de todo, los sistemas complejos requieren, para su preservación, de mecanismos que puedan autorregenerarse continuamente. De este modo pueden hacerse antifrágiles.

En la naturaleza no existe complacencia sino redundancia, una propiedad de los sistemas vivos contra el riesgo. El cuerpo tiene dos riñones, dos pulmones, circulación cerebral alterna (el polígono de Willis), sinusoides hepáticos. Las varias «capas de redundancia» son una propiedad fundamental de los sistemas naturales. La redundancia «puede parecer un desperdicio si no sucede nada inusual. Excepto que, usualmente, sucede algo inusual». ${ }^{6}$

Los sistemas y procesos biológicos de los seres vivos están expuestos a los retos de un medio siempre cambiante. Para adaptarse, crean variantes que les confieren antifragilidad. Así es como evolucionan. Un ejemplo son las proteínas con regiones flexibles, que pueden someterse a alteraciones funcionales en respuesta al estrés ambiental. De este modo logran «reparaciones improvisadas», un automantenimiento mediante composturas sencillas. ${ }^{7}$

Así es como las estructuras biológicas se hacen difíciles de inactivar o destruir, aunque de todas formas, al llegar sus procesos al punto sin retorno, su suerte esté echada. O se endurecen por un tiempo (se hacen robustas) o permanecen iguales (frágiles) y se degradan. Como 
ejemplos, en pocos meses las células cancerosas derrotan a las quimioterapias; en pocos días de tratamiento insuficiente las bacterias se hacen resistentes a los antibióticos. ${ }^{7}$

La emergencia de condiciones nuevas requiere adaptación, como la de aquellas bacterias que se adecuaron a usar el Nylon ${ }^{\circledR}$ de nuestros desechos industriales como fuente de nitrógeno y carbono. ${ }^{8,9}$

El coronavirus SARS-CoV- 1 se hizo antifrágil durante la epidemia de 2003 creando un nuevo antígeno de superficie a partir de un genoma que se conformó como patrón común. ${ }^{10}$ Los coronavirus tienen tendencia a recombinarse y mutar con mucha frecuencia.

No es de extrañar entonces la antifragilidad del SARS-CoV-2. El virus mismo es frágil, se destruye fácilmente con agua y jabón, o con alcohol-gel en concentración adecuada. Pero la información codificada en él durante las mutaciones lo hace antifrágil; puede hacer algo más que reaccionar mediante mutaciones. Tiene «una propiedad incorporada [literalmente, la flexibilidad de sus proteínas y procesos] que le permite encontrar soluciones frente a la adversidad». ${ }^{7}$

\section{RESILIENCIAY ROBUSTEZ NO BASTAN}

Por el contrario, los sistemas diseñados por el hombre buscan la economía, la simplicidad y la elegancia, dicen los matemáticos. Nada que falte, nada que sobre, nada redundante, nada de repuesto. Habitualmente los sistemas resilientes o robustos no son dañados por la volatilidad del desorden, hasta que llegan al punto en que sus capacidades son rebasadas.

Ante el repunte de las hospitalizaciones, en México se ha tenido que convocar a pasantes en servicio social (estudiantes en el último año antes de graduarse), cuyo único requisito es presentar su carta de término, la Carta de pasante, con la promesa de ofrecerles «equipo de protección personal de alta calidad y capacitación intensiva en el manejo integral del paciente con covid» (cursivas mías), señala la convocatoria. ${ }^{11}$ ¿Qué experiencia puede tener un estudiante de medicina, un estudiante no graduado? ¿Qué tipo de atención puede ofrecer con esa «capacitación intensiva» pero brevísima?
Hay aquí dos perspectivas que es preciso considerar; la del Estado que los convocó y la de los estudiantes que aceptaron, con no poca exaltación. En cuanto a la primera perspectiva, recordemos el uso militar de niños soldados durante la Segunda Guerra Mundial por Alemania, Japón, Rusia, Polonia y el Reino Unido. En la medida en que avanzaba el conflicto fueron reclutados cada vez más jóvenes, de 16, de 15, de 14 años. En México el reclutamiento transitó rápidamente de especialistas a médicos generales a pasantes, en un intento por subsanar las carencias.

De la segunda perspectiva, de los pasantes, una fuente anónima me ha referido que algunos se enlistaron con entusiasmo para atender enfermos con COVID-19. En la efervescencia del apremio, y antes de que iniciara el programa de vacunación, el ímpetu de esos jóvenes todavía no médicos, bien pudo en alguna medida deberse al glamour, poco meditado, del lugar común, del héroe que no se amedrenta ante nada.

Esto me hace recordar las expediciones conocidas como la Cruzada de los Niños, que partieron de Alemania (Colonia) y Francia (Vendôme) hacia Tierra Santa en 1212, probablemente alrededor de la Pascua o Pentecostés (un detonador interesante de la acción) en busca de la Santa Cruz. Alguna fuente refiere «eodem anno fuit iter stultorum puerorum» («ese mismo año fue el camino de los niños tontos»)..$^{12}$ Unas fuentes se inclinan a adscribir el movimiento a inspiración divina; otras, que supieron de su triste final, lo conciben como obra del demonio.

Muchos perecieron de hambre y sed sin llegar a su destino, o fueron despojados por los lombardos. De los que partieron por mar unos naufragaron, otros fueron vendidos por piratas como esclavos, y las doncellas violentadas. Pocos regresaron a casa, algunos lograron llegar a Roma. De acuerdo con el historiador medievalista Dana Munro, aunque los niños deseaban, en su entusiasmo, unirse a las diferentes avanzadas, «es difícil explicar la aquiescencia de sus padres o la opinión favorable de clérigos letrados». Munro menciona también una cita del papa Inocencio III, la exclamación «estos niños nos han avergonzado, porque mientras nosotros dormimos, ellos se apresuran a re- 
cuperar la Tierra Santa». ${ }^{12}$ Estas dos analogías muestran cómo, ante la catástrofe, un sistema frágil intenta reforzarse con recursos también frágiles.

Pero volvamos al presente y hagamos ahora un experimento mental. Conocemos (sabemos de) la enfermedad, pero no sabemos cómo reaccionará nuestro cuerpo. ¿Qué tipo de inducción de Pavo aplicaríamos para decidir, ante nuestros síntomas que se agravan? ¿La disponibilidad de camas? ¿El hospital mejor equipado? ¿El mejor manejado o el más cercano? ¿La reputación o la distancia? ¿El costo? ¿La intensidad o la velocidad de evolución del cuadro clínico en función de la distancia? ¿El consejo de un colega? ¿Esperar y ver?

Además, necesitaríamos la suerte de que el hospital público más cercano tuviera alguna robustez; cama disponible, medicamentos e insumos y el personal adecuado. Si se trata de una institución privada, se necesitaría disponibilidad, pero también que el seguro cubriera totalmente los costos, que han ido de $\$ 433,000.00$ MXN (\$21,936.00 USD) por hospitalización a un millón de pesos en caso de requerirse cuidados intensivos y hasta 3.67 millones (\$185,917.00 USD) en caso de intubación. «El caso con el mayor monto de indemnización reportado ha tenido un costo de 25.52 millones de pesos $(\$ 1,292,806.00$ USD)». ${ }^{13}$ (Las tasas cambiarias son de diciembre de 2020). Por cierto, uno de los varios términos para 'suerte' en latín es 'alea', de donde 'aleatorio'.

\section{ANTIFRAGILIDAD PROFESIONAL}

La ilusión de robustez tiene como efectos la tranquilidad y la rutina; viene del deseo de mantener la estabilidad. Ilusión y deseo son particularmente fuertes a medida que el cirujano se va haciendo viejo y confía en su experiencia de cisnes blancos.

El Cirujano Inductivista estaba tranquilo, siempre había hecho las cosas así y siempre le habían salido bien, pero la voz de su experiencia lo ha puesto a merced de los sistemas mexicanos de salud, público y privado. El Cirujano Inductivista no puede permanecer, sin embargo, en la luna. Si hubiera en la Tierra un
Mar de la Tranquilidad no dejaría de ser mar. El Océano Pacífico es todo menos pacífico. La tranquilidad aminora la capacidad de adaptación y respuesta, produce individuos complacidos y disfuncionales ante la «nueva» realidad, que no es nueva sino siempre cambiante. ${ }^{14} \mathrm{Ya}$ decía Heráclito que «el Sol no es nuevo cada día, sino continuamente nuevo». ${ }^{15,16}$

Por otro lado, resiliencia y robustez pueden permitir renacer de las cenizas, pero hasta un límite. En las mitologías existen los indestructibles, en la vida real no. El cirujano no puede dejar de operar. No puede resignarse, como psicoterapeuta, a dar consultas virtuales. Tiene que hacerse antifrágil; depende de su arte, el ars chirurgia.

El cirujano antifrágil tendrá que olvidar la época estable, ya no vivimos en ella. Además de subsanar las limitaciones de un Estado frágil, tendrá que avenirse a las medidas adaptativas de las instituciones privadas, que no velarán por su bienestar (no son asistenciales, son negocios). Que se protegerán en detrimento de las partes (el cuerpo médico y demás personal) que dejen de ser funcionales (que enfermen o mueran); aquéllos que, de ser activos (que tienen valor, que generan ganancia) se conviertan en pasivos (que significan gastos). Un cirujano enfermo, que no puede trabajar, pierde valor monetario; para «su» hospital y su familia es un pasivo.

El primer paso hacia la antifragilidad es amortiguar la caída, el daño emocional de la aversión a la pérdida. Lo perdido, perdido está. Esto implica la domesticación de las emociones que, como la incertidumbre, no pueden eliminarse. No digo que sea fácil, nadie es inmune y en esto no hay recetas, las emociones son parte de la racionalidad. Pero lo roto tiende a permanecer roto, y la fragilidad castiga igual que una enfermedad terminal. ${ }^{17}$

Como segundo paso para no seguir a merced del sistema, el cirujano tendrá que hacer un control de daños y diseñar estrategias de supervivencia; confiar en su habilidad para improvisar, que otras veces le ha permitido resolver eventos transoperatorios adversos. Le será indispensable acumular redundancia de recursos para continuar operando, redundancia en equipos y estructuras de respaldo. Equipos de protección personal $\left(\right.$ Tyvek $\left.^{\circledR}\right)$, mascarillas 
(N95, KF94, FFP), caretas, guantes y otros. Y una lista de proveedores confiables. Además, plataformas de comunicación virtual y los Correspondientes equipos de cómputo con varios niveles de almacenamiento de datos, externos y en diferentes sitios o nubes.

El cirujano está en desventaja frente al aumento del costo de los materiales y servicios en que él mismo se apoya para dar servicio y generar sus ingresos. Pero lo redundante cuando no hay necesidad se vuelve indispensable cuando hay desabasto. Lo que parecían pasivos, se convierten en activos. Mejor redundancia entonces que carencia, sobre todo cuando el libre mercado disminuye las existencias y manipula los precios en detrimento de sus ingresos, buena parte de los que ahora tendrá que destinar a la antifragilidad si quiere mantener su operatividad.

El tercer paso hacia la antifragilidad incluye estructuras y redes de apoyo entre colegas. Es ahí donde entra en juego la cooperación para compartir información cambiante. La información es un insumo. El cirujano aislado es frágil.

No menos importante, el mejor activo es uno mismo, el cirujano robusto y antifrágil que invierte en su propia salud, en mejorar su calidad de vida, en su autoconocimiento, convirtiendo el encierro pandémico en esa introspección honesta y profunda para la que antes no tenía tiempo. De ahí sacará la resistencia.

Para hacerse antifrágil, el cirujano tendrá que considerar esta pandemia como un muy largo transoperatorio. Tendrá que hacerse experto en estrategias de cambios y ajustes, de reparaciones improvisadas y reevaluaciones constantes.

Y aun cuando la pandemia se convierta en endemia, habremos de tener presente $\mathrm{La}$ Peste de Camus, pues ya se han dado varios episodios de disminución de contagios durante los cuales la gente sale a celebrar como si nada, una actitud emocionalmente entendible pero racionalmente inadecuada. Termino citando el final de su novela, de 1947, todavía válida:

«Escuchando, en efecto, los gritos de alegría que subían de la ciudad, Rieux [el doctor] recordaba que esta alegría estaba siempre amenazada. Pues él sabía lo que esta muchedumbre alegre ignoraba y que puede leerse en los libros, que el bacilo de la peste no muere ni desaparece jamás, que puede permanecer durante décadas dormido en los muebles y en la ropa, que espera pacientemente en las habitaciones, las bodegas, las maletas, los pañuelos y los papeles y que, tal vez llegaría el día en que, para desgracia y enseñanza de los hombres, la peste despertara sus ratas y las enviara a morir en una ciudad dichosa. $\rangle^{18}$ (Mi traducción.)

\section{REFERENCIAS}

1. Taleb NN. The Souk and the office building. En: Antifragile: things that gain from disorder. Nueva York, Random House; 2012. p. 15.

2. Russell B. On induction. En: The Problems of Philosophy. 2a ed. Oxford, Oxford University Press; 1998 reimpr. 2001. p. 33-38.

3. Taleb NN. The Souk and the office building. En: Antifragile: things that gain from disorder. Nueva York, Random House; 2012. p. 20, 97-115.

4. Ximénez-Fyvie LA. Llamado a las autoridades para solucionar de inmediato el desabasto generalizado de medicamentos básicos para ayudar a pacientes COVID. Twitter [Internet] 202007 26. Consulta del 202011 08. Disponible en: https://twitter.com/ Iximenezfyvie/status/1287394294656045059

5. Colectivo Cero Desabasto. Desabasto de medicamentos en México: 2do reporte cuatrimestral 2020. Ciudad de México, octubre 2020. Twitter [Internet] 20201026. Consulta del 202011 08. Disponible en https://twitter. com/cerodesabasto/status/1320824870377279488/ photo/1

6. Taleb NN. Overcompensation and overreaction everywhere. En: Antifragile: things that gain from disorder. Nueva York, Random House; 2012. p. 55-65.

7. Danchin A, Binder PM, Noria S. Antifragility and tinkering in biology (and in business) flexibility provides an efficient epigenetic way to manage risk. Genes (Basel). 2011; 2 (4): 998-1016. doi: 10.3390/genes2040998

8. Negoro S, Taniguchi T, Kanaoka M, Kimura H, Okada $\mathrm{H}$. Plasmid-determined enzymatic degradation of nylon oligomers. J Bacteriol. 1983; 155: 22-31. doi: 10.1128/jb.155.1.22-31.1983

9. Ohno S. Birth of a unique enzyme from an alternative reading frame of the preexisted, internally repetitious coding sequence. Proc Nat Acad Sci USA. 1984; 81 (8): 2421-2425. doi: 10.1073/pnas.81.8.2421

10. Yap YL, Zhang XW, Danchin A. Relationship of SARS$\mathrm{CoV}$ to other pathogenic RNA viruses explored by tetranucleotide usage profiling. BMC Bioinf. 2003; (4): 43. doi.org/10.1186/1471-2105-4-43

11. Valadez B, Ríos C. En CdMx reclutan hasta pasantes para tratar covid-19 ante saturación hospitalaria. Diario Milenio [Internet] 202011 30. Disponible en: https://www.milenio.com/politica/reclutan-medicos- 
enfermeros-pasantes-cdmx-covid-19 [Consulta del 202012 01].

12. Munro DC. The Children's Crusade. The American Historical Review. 1914; 19 (3): 516-524. En: https:// www.jstor.org/stable/1835076 [Consulta del 202012 01].

13. Mendoza-Escamilla V. Aseguradoras advierten saturación de hospitales privados por Covid-19. Forbes México. [Internet] 202012 04. Disponible en: https:// www.forbes.com.mx/negocios-covid-19-saturacionhospitales-privados-aseguradoras/ [Consulta del 2020 12 07].

14. Campos A. Reconstruir algún orden en el caos. Problemas del cirujano COVID. Cir Gen. 2020;42(2):176-181. doi:10.35366/95378.
15. Heráclito de Éfeso. En: Diels H. Fragmenter der Vorsokratiker. (2a ed.) Vol. 1. Berlín, Weidmannsche Buchhandlung; 1906. p. 62-64.

16. Heráclito de Éfeso. En: Mondolfo R. Heráclito. Textos y problemas de su interpretación. (13a ed.) Ciudad de México, Siglo XXI editores; 2007. p. 31-32.

17. Taleb NN. On the irreversibility of broken packages. En: Antifragile: things that gain from disorder. Nueva York, Random House; 2012. p. 178 y ss.

18. Camus A. La Peste. París, Éditions Gallimard; 1947. La cita es de la Colección Folio; 1987 p. 279. Versión en español: La Peste (tr. Rosa Chacel). Barcelona, Editorial Edhasa; 2005. English version: The Plague [Translated by Stuart Gilbert]. The Modern Library, Random House, Inc. 1948. p. 254. 